\title{
Exploring Successful Small Urban Spaces' Criteria with Emphasis on Cultural Context
}

\author{
Parvin Partovi, Kebria Sedaghat Rostami, Amir Shakibamanesh
}

\begin{abstract}
In the crowded cities of the present age, public spaces can provide a quiet area away from the hustle and bustle of the city that citizens can interact with by incorporating utility features and meeting human needs and Relax there. Small urban spaces are among the most important and effective urban spaces to achieve this goal. Because these spaces due to their small size and lower costs (compared to larger spaces) for construction can be created in large numbers and distributed throughout the city. In this way, citizens will be able to reach a public urban space on foot in a short time. If these spaces are well designed, they can encourage people to stay in and interact with each other. It is not difficult to identify and experience high-quality successful places, but identifying the reasons for their success is difficult and even more difficult, understanding if similar spaces in other places can be considered successful. This question is important because public space with deep social content is considered a cultural product. Public space is the product of the historical and socio-cultural forces of society. Therefore, one of the most important issues that should be considered in the study of public spaces and the reasons for their success is the cultural context. In Iranian cities that have been influenced by the values and principles of Islam, recognizing Islamic principles and their role in shaping public spaces can lead us to desirable results. The purpose of this article is to develop a conceptual model of successful small urban spaces with an emphasis on cultural issues, especially in Iranian-Islamic cities. In this regard, the effective criteria for the success of urban spaces in general and small urban spaces in particular in the two categories of Western countries and Iranian Islamic cities were examined and then, taking into account the criteria derived from cultural theorists, the conceptual model of research with 38 subcriteria is provided.
\end{abstract}

Keywords: contextualism; culture; successful space; urban space

\section{INTRODUCTION}

Different scales can be identified for urban spaces due to many issues, such as function, size, capacity, and their location in the city, especially concerning urban divisions and hierarchies [1]. Since each person has different needs, one space cannot meet all the needs of all users. Therefore, a city must offer different types of public spaces [2]. Public spaces have various scales from small spaces city.

Small public spaces include features such as small size, large accessibility, and many facilities. These spaces provide attractive views and easy access. Unlike large urban parks and squares or other regional public spaces, small public spaces mainly consist of small squares and small parks around blocks and open spaces between buildings. In terms of spatial pattern, small public spaces (as opposed to the linear space of streets or alleys) are primarily blocks or dots. In terms of space size, the criteria vary slightly between countries and regions [3].

Small scale-spaces are very important. Rob Carrier also believes that traditional small-scale urban spaces have proved to be a place of communication for thousands of years; Spaces with a human scale that can be easily walked. Numerous activities take place in these spaces and group activities including sports and games, chess, and card games are prominent in small and medium public squares [4]. People need small spaces because they provide a place to relax and, most importantly, spontaneous social interactions. Social interaction is the mainstay of social capital. Places with good social capital are sustainable and successful. Building social capital is not very easy, but it is easy to create spaces that can shape social capital. Small urban spaces are some of the best spaces for this aim. In addition, the most essential need in most cities is spaces that everyone can access. Ideally, no one should be more than 1.4 miles (about 2250 meters) away from a small space [5].

\subsection{Small Public Space Theorists}

The issue of the scale and size of public space has always been a thoroughly studied and analyzed subject; for example, by people like Jacobs (1961), Seymour (1969), Whyte (1980 and 1988), Cooper Marcus and Francis (1998) and Gehl (1989-2011). Jane Jacobs has conducted a comprehensive social analysis of small pedestrian spaces, saying that pedestrians are small but penetrate the entire city and often go beyond a narrow corridor and act as small public squares [6]. Seymour (1969) was the first theorist that used the term 'small urban space' to change the prevailing view of small urban parks. He mostly referred to small urban spaces as urban parks and children's playgrounds. Seymour points out that to maintain our cities and make them habitable; we need positive programs that provide beauty, fun, and enjoyment to the inhabitants of our cities. Meanwhile, the proper use of small urban spaces can significantly contribute to this process.

William Whyte carried one of the most extensive projects to investigate the causes of the success of small urban spaces out. Whyte believes that people use spaces in which they feel comfortable and can easily move around. He believes that the multiplicity of small spaces is enormous and not only the people who use it enjoy it, but all the passers-by and even all the residents of the city who are aware of its existence. In a city, such places that are built at low costs are economical. It can be said that Whyte believed that people are attracted to other people [7]. According to Whyte, the presence of a large number of women, the existence of the right to choose between sun and shadow, large seating space, the use of water sound and visual beauty, the absence of harmful people, and the phenomenon of triangulation make small spaces successful. A great change was made after Whyte's innovative research. Zukin believes that Whyte was 
an inspiration to many urban designers and planners and his research changed the way we study cities [8].

Seeking a more active public life in the harsh climate of Scandinavian cities, Jan Gehl used Whyte's method to study Danish urban spaces. He prefers small-scale spaces and says that in narrow streets and small spaces we can see the buildings, details, and people around us at a short distance. On the contrary, a large scale leads to confusion of people [9]. Cooper Marcus and Francis (1976) conducted another similar study. During their research, they have identified different types of public spaces (six types), three of which are small spaces namely street square, which is a part of public open space that is very close to the sidewalk, is open, and has a close connection with the street. Such spaces are usually used for short periods to sit, wait and watch; Common courtyard (collective space) is part of a building complex and its main use is the definition of entrance space. It is usually privately owned but publicly available; Passage/related to public transportation (temporary stop space) which is a square-like space that has been created for easy access to the entrance and exit of crowded public transportation terminals. Although the predominant activity is traffic, terminal users sometimes attract traveling vendors and viewers.

\section{URBAN SPACE DESIGN CONCERNING CULTURAL CONTEXT}

One of the important cases in postmodern urban planning is the organization of a suitable space for the social and cultural context of the city [10]. Culture in its simple definition is the discipline that connects people with the outside world [11]. In general, it is believed that the physical product of each society reflects its culture. The most important physical product of a society is the body and urban architecture that society creates for itself to grow and transfer culture from one generation to another [12]. Contextualists believe that the analysis of a physical phenomenon is possible when we know how it is perceived in that culture. Therefore, the context-oriented urban planner should be able to understand the characteristics of a place and make it a part of his design process [13].

The cultural system and social relations are interconnected. On the one hand, culture is the product of social relations and the establishment and continuation of social relations strengthen values and norms or culture. On the other hand, culture determines the conditions and manner of formation of social relations. Since the main function of public space is to prepare a context for the presence of people, a social and cultural relationship takes place in space [14]. Space becomes a place where cultural and physical characteristics are combined with the emotional perceptions and functional needs of individuals. This is why the revitalization of places without considering cultural features leads to the no-place [15].

Meanwhile, the task of urban planners is to create a place that provides the best fit between the cultural and physical contexts and the needs and expectations of users [14]. In the next step, the design of the space is important. Design should provide appropriate opportunities for the expression of culture, and users with different social groups and different cultures of users from the culture of designers should be considered.

\subsection{Culture and Urban Space Theorists}

Paying attention to culture in recognizing and explaining the city is not a new issue. Many theorists have paid attention to the importance of the cultural dimensions of the city since the beginning of the emergence of industrial cities in the nineteenth century [16]. John Ruskin (1818-1900) is undoubtedly one of the most influential thinkers and critics of the nineteenth century, whose ideas greatly influenced early twentieth-century artists. Ruskin greatly influenced his disciple William Morris. William Morris Davis (1896-1834) does not assent to the uniformity of urban spaces. The views and thoughts of Ruskin and Morris were the results of a comparison between the past and the present. Another thinker in this field is George Simmel (1918-1858). He was the first researcher to take the biological experience of modern urban culture seriously. He claims that the life and culture of those who live in metropolitan areas have been formed mainly through people's reactions to a set of intense stimuli [17]. His attention to the characteristics of life in metropolises influenced theorists such as Walter Benjamin (1892-1940). Benjamin was interested in the interrelationships of the city as a meaningful space of several layers. Like Simmel, he considered the city and the architecture of the city as the main component of modernity [18].

Roland Barthes (1980-1915) is also a theorist whose writings have greatly influenced cultural studies. His attitude towards culture is from the perspective of the meaningmaking process. In addition, among thinkers interested in culture and the city, Claude Levi Strauss (1908-2009) is known for introducing structuralism attitudes and methods into anthropology. He sees culture as a set of symbolic systems, all of which he believes aim to express aspects of physical reality and social reality. Strauss believes that to understand any culture, its underlying structure must be understood [19].

Edward T. Hall (1914-12009) is also an anthropologist who is interested in intercultural studies. In his view, culture is the information and methods shared about coding information and saving and retrieving it [20]. His ideas on various types of urban spaces are very valuable. In addition to Hall, Lewis Mumford (1898-1990) is one of the culturists who have valuable theories about the city. He distinguishes the city in two ways: one is the physical means including the fixed body, the stable housing, and permanent installations, and the other is the non-physical means including the division of social labor which guarantees not only economic life but also cultural processes [21]. Sharon Zukin (1946present), like Mumford, has dealt with the relationship between the city and culture [22]. Finally, we can refer to Amos Rapaport (1921-present) who has different theories about space that emphasize the cultural dimension. He believes that the cultural context is very important because it 
describes the events [23]. Tab. 1 shows the views of these theorists.

Table 1 Theorists' views on culture, city, and urban space

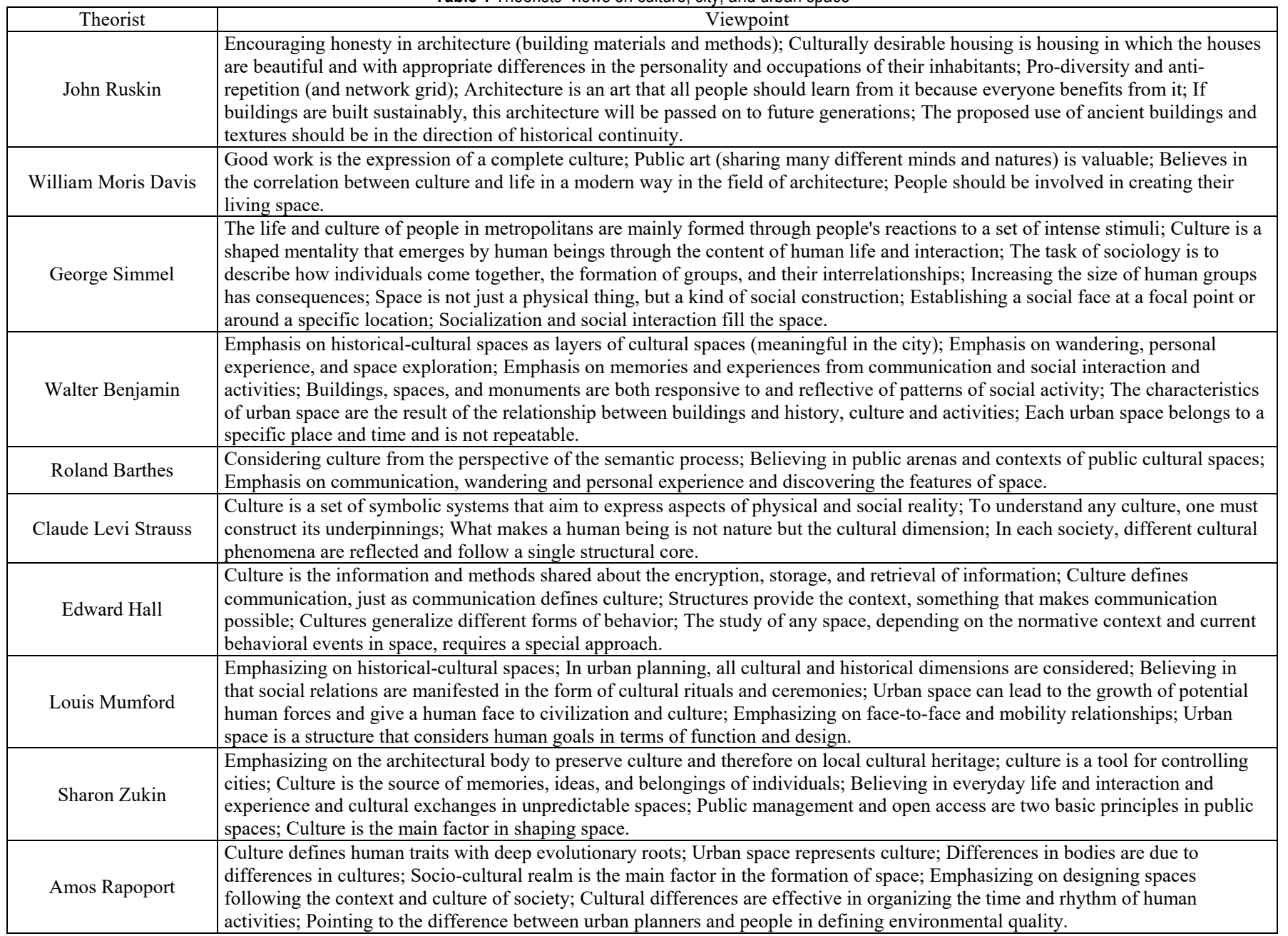

\section{THE EFFECTIVE FACTORS IN THE SUCCESS OF URBAN PUBLIC SPACES}

In this section, the effective factors in the success of urban public spaces with an emphasis on small urban spaces are proposed. Successful outdoor space has an important effect on people's feelings. Design based on the needs and desires of users is necessary. Since the definition of human needs is different in various cultures and due to the deep cultural differences between Western countries and Iran, there is no doubt that the characteristics of public spaces in these two cultures are different from each other. Of course, similar criteria can be found, but due to differences in the historical, cultural, and spiritual values of countries, it is necessary to examine the characteristics of the success of public spaces separately from Western countries and Islamic Iranian cities.

From the perspective of perception in Western countries, readability is an important factor in the design of urban spaces. Therefore, it is necessary to pay attention to the design of micro-spaces, human scale, space size, and appropriate spatial scale. On the other hand, security is one of the most important factors to attract people to the public space at any time of the day [24]. In this regard, Cremona believes that the presence of women can be a measurement of security. From the point of view of Iranian researchers, readability is also important due to the four factors of space size, integration (existence of coherence in the field space, avoiding excessive fragmentation of space, and the possibility of creating a mental image of the whole space), enclosure and spatial determination (Determining the borders of urban squares), and giving meaning to space [25]. Security is another important factor. The existence of areas and equipment required by different age or social groups and the existence of spontaneous or organized activities to attract and retain citizens are other important issues that allow the presence of individuals [26].

About small urban spaces in particular, in Western sources, factors such as legibility, visibility for pedestrians, and functional accessibility have been mentioned. Whyte also considers the high presence of women and the absence of homeless people and addicts to be effective in the success 
of space [6]. In Iranian sources, in addition to referring to these two factors, it is stated that the boundaries of the squares should be clear and understandable to the people inside it in a way that induces the feeling of presence in space $[11,25]$.

Besides, from the social dimension, several factors affect the success of the space. The formation of social interactions, vitality, and attracting people are the most important features of social space [4]. A successful place is a place that is more alive and active, and the diversity of space users, activities and relationships, and social activities can be seen in it [27].

In Iranian-Islamic cities, the first and most important factor in the success of public space in terms of social dimension is sociability. The possibility of the presence of different individuals and social groups and meeting the needs of all individuals, including material, psychological, and spiritual needs are important criteria for the sociality of the space. Meanwhile, reminding, gentleness with the senses through pleasure, respecting human beings in buildings and behaviors and against the law [28], and interacting with all people are among the characteristics that lead to the spiritual growth of individuals. In addition, space should be lively and provide the possibility of staying or relaxing [25]. One of the qualities that affect the creation of vitality is diversity. We must increase the diversity in the function, activities, times of using the space, and groups of space users [25]. Moreover, vitality in the urban space must be met by criteria such as the desired urban form, preservation of cultural identity and historical continuity; Adjust the space according to the behavioral pattern of people; Providing facilities for happiness and leisure; Provide suitable places for both social and economic activities [29].

In addition, the design of small urban spaces emphasizes intimacy and human connection among space visitors [30]. Moreover, the possibility of social life versus private life and a sense of closeness to the place is essential in the acceptance of space by people and its success as the result [6]. In Iranian cities, local squares as a kind of small urban space bring peace to their users. In addition to tranquility, intimacy and the possibility of dominating the space are other important features of local squares and all residents of the neighborhood should feel a sense of belonging to the local square [11].

In terms of function and accessibility, Western sources state that the position of public space in the spatial hierarchy shows how much space is used. As far as the amount of space use is related to its location, two effective factors can be mentioned: its location concerning the surrounding environment and neighborhoods and how to access space. Space should have strong connections with the surrounding areas and provide easy and unobstructed access for all people. Whyte (1988/1980) also emphasizes the importance of paying attention to street communication due to the inviting perspective (open and transparent street communication and appropriate entrance design). In addition, successful spaces are visible to users, have a suitable entrance and access to public transport, and provide enough parking lots. Another important design priority in public spaces is the safety factor that directly affects the use of space. Proper organization of pedestrian and bicycle paths and protection against accidents lead to a sense of safety in public space [31].

The functional dimension also includes how the site is used (uses and activities). Successful open spaces are those that meet the needs of society and provide the context for economic, social, and cultural activities [33]. In addition, between different parts of a space, the design and use of public space can be done according to the center and edge. Edges are preferred for both sitting and standing by people, and the presence of elements and focal points also attracts more people [34]. Activities also play an important role in defining public urban space. Containing mixed activities is the key to successful urban spaces [33]. In this regard, Whyte believes that the elements should be located in a way that greatly increases the possibility of activity around them [6]. Diverse activities in space can take the form of active engagement (such as running and being able to explore the environment) or passive engagement (such as looking at people and the public arts) [35]. In addition, having a comfortable space and providing user comfort is a key factor for its success. Feeling comfortable includes various factors such as providing the necessary facilities for people, availability of sufficient and comfortable place to sit, feeling of safety and security, and cleanliness. Mental comfort can be a prerequisite for comfort. Relaxation and release of physical and psychological pressures lead to comfort in public spaces. The first functional factor influencing the success of Iranian-Islamic spaces is providing easy and unimpeded physical access for everyone. Another important factor is visibility and visual access. Providing safety through traffic control and connecting to surrounding areas are also among the other effective factors in this field. In this regard, special emphasis is on providing access for pedestrians and access to public transportation [36]. Another very effective factor is the space function and activities. By defining multiple functions, traditional Iranian squares have induced values and controlled the behavior of users, and have helped identify and increase residents belonging to space [37]. These spaces must be creative in creating different functions and meeting the needs of different age or social groups [28] and should be able to provide both social and economic activities [25]. In addition, meeting the needs of play and entertainment and the existence of spontaneous or organized activities to attract people have special importance in achieving a successful public space [26].

Functional factors also play an important role in the efficiency of small urban spaces. Factors such as visibility, maximum physical accessibility [38], proximity and ease of access, location near sidewalks and in connection with the street [6], visual communication with the surrounding network, defining the square entrance [7, 24], providing parking and managing motorcycle parking [3] are influential. On the other hand, diversity in the configuration of spaces, the presence of planned steps and activity edges and attractive focal elements, and the variety and comfort of sitting areas lead to the presence of more people in the space [7]. Successful small space provides functions responding to the needs of the surrounding population and provides the 
ability to adapt to a wide range of different functions [38]. Mixed-uses ensure the continued use of public squares throughout the day [38]. The function of the surrounding buildings also has an important role in the dynamics of the space. Moreover, proximity to natural factors, the presence of trees and other plants, the use of adequate sun and wind, and playing with light and shade help to improve the efficiency of small public spaces [6]. In addition, to promote a sense of safety, it is important to ensure that views from inside of the park are not completely closed [30]. In this regard, some cases have been mentioned in Persian sources too. Pakzad considers successful local squares as quiet and not too crowded in which residents' supervision is evident and activities have a local scale. Besides, all people should have quick and easy access to space without movement barriers, car movements should be minimized and disturbing activities with loud noises should not be established [11]. Providing appropriate equipment and furniture in such spaces is important too and there should be facilities to sit in the sun or shade [25].

From a visual landscape point, from Sitte to Moughtin, beauty and originality have been identified as important factors for the success of public areas [7]. Among these, the most important factors that play a role in the beauty and innovation of public spaces are attractive buildings and landscapes, beautiful architecture of the surrounding area, enclosure, proper proportions, appropriate and varied paving, proper landscape arrangement, designing due to topography, designing beautiful furniture, using color and light in space, the difference in level, and visual complexity and diversity $[7,24]$. The presence of aesthetic elements also affects enjoying of public space. Appropriate scale, aesthetic quality, and rich emotional experiences are effective in the sense of pleasure [32]. Considering aesthetic factors is the most important factor in Iranian-Islamic urban spaces too. This element includes factors related to beauty and visual attraction such as spatial diversity, proper body, proper flooring, beautiful and desirable landscapes, and visual [18]. In Islamic texts beauty, respect for the human being, creativity and perfectionism and modernity, and paying attention to meaning [28].

Successful small squares also tend to create visual beauty. Therefore, it is suggested that the width and length of the site be appropriate [30]; Of course, a strong sense of enclosure is not necessary for a small successful public space. It is also necessary to pay attention to historical, cultural, and geographical contexts, legibility of the environment, and increasing diversity and avoiding repetition in place [38]. In Iranian-Islamic cities, the small urban space is physically geometrically specific and should be stress-free in the physical elements [25]. In addition, space should have a proper enclosure and a human scale. In addition, entrances should be defined, not inviting; Of course, space should be attractive for residents [18].

From an environmental point of view, every public space should have a comfort zone in different weather conditions. The main factors that affect a person's outdoor comfort are temperature, sunshine, humidity, and wind. People are looking for places that are safe from these factors; Therefore, these issues should be considered when designing the space and locating the sitting spaces. In addition, there should be plant diversity, attention to the height and materials of the surrounding buildings and the orientation of the field for proper lighting, using the element of water, and the protection of people from pollution [6].

In Iranian texts, the existence of environmental comfort and enjoyment of climatic conditions is mentioned as a factor in the success of urban spaces and it is stated that the fields should benefit from light, sun, shadow, and the sound of the wind among the leaves. In addition, preserving the environment due to Islamic instructions, peaceful coexistence with nature, use of natural elements and water [26] are very important in Islamic cities.

In small urban spaces, Whyte believes that sun (especially in winter), wind, water (to stimulate the senses through sound, seeing, and feeling), and trees (due to the creation of shade and natural environment) contribute to the success of space [7]. Regarding the importance of natural elements in Iranian-Islamic cities, it is also stated that light, sun, shadow, and the sound of wind among the leaves should be considered in the squares [25].

In the time dimension, using space at different hours, days and seasons have a great impact on its success [32]. In this regard, Montgomery emphasizes the existence of active activities in the evening and night. Rapaport raises the issue that cultural differences are effective in organizing the time of activities and consequently the desirability of urban space [23]. In Iranian-Islamic cities, characteristics such as maintaining historical continuity, variety in times of using space, and special function in specific or permanent times can be expressed. Flexibility is important in the role, meaning, and function of urban squares, and the square stabilizes its character over time. Different activities and actions also change easily based on needs, time, etc. [25]. Therefore, accompanying time and history and respecting cultural characteristics are valuable principles in the success of Iranian-Islamic public spaces [28]. Time-related factors have not been specifically addressed concerning the success of small urban spaces. This is because the importance of the variables of this dimension is the same in all scales related to space and all types of spaces reflect change over time.

From the management dimension perspective, it can be said that proper management of spaces leads to improving life, work, and leisure experiences. In this regard, long-term planning, short-term measures, respecting mutual rights of space and users, proper management, the absence of barriers to bureaucracy and encouraging local community participation in place management, management coordination to maintain space and create a sense of security and safety, the existence of regulations for the use of space, flexibility in decision-making at all stages, and the existence of dynamic programs are important [7]. In contrast, lack of investment and lack of coordination between activities and stakeholders can lead to reducing quality in public spaces. In addition to the mentioned factors, urban management should maintain space. High-quality maintenance and cleaning the space make it pleasant to the public [39]. 
In Iranian-Islamic cities, one of the most important factors that help the space to achieve success is managerial factors. Urban space management must perform its duties well in all stages, including planning, implementation, organization, policy-making, and control and supervision [40]. In this regard, space is obliged to respect the rights of city residents and the rights of nature, there should be coordination between different management departments and between management institutions and city residents, proper management should be done in all sectors and there should be space monitoring. Also, in addition to the participation of groups who benefit from space and local management, continuous control and management, unified and centralized management along with paying attention to the council structure of management [28].

Concerning the qualities of the managerial dimension, there is less content that is specifically dedicated to successful small urban spaces. This is because space management to maintain it in all spaces requires managerial cohesion and participation of individuals. In this regard, Pakzad [18] emphasizes the role of local people in the management and monitoring of space and believes that successful local squares are spaces where residents' control is evident.

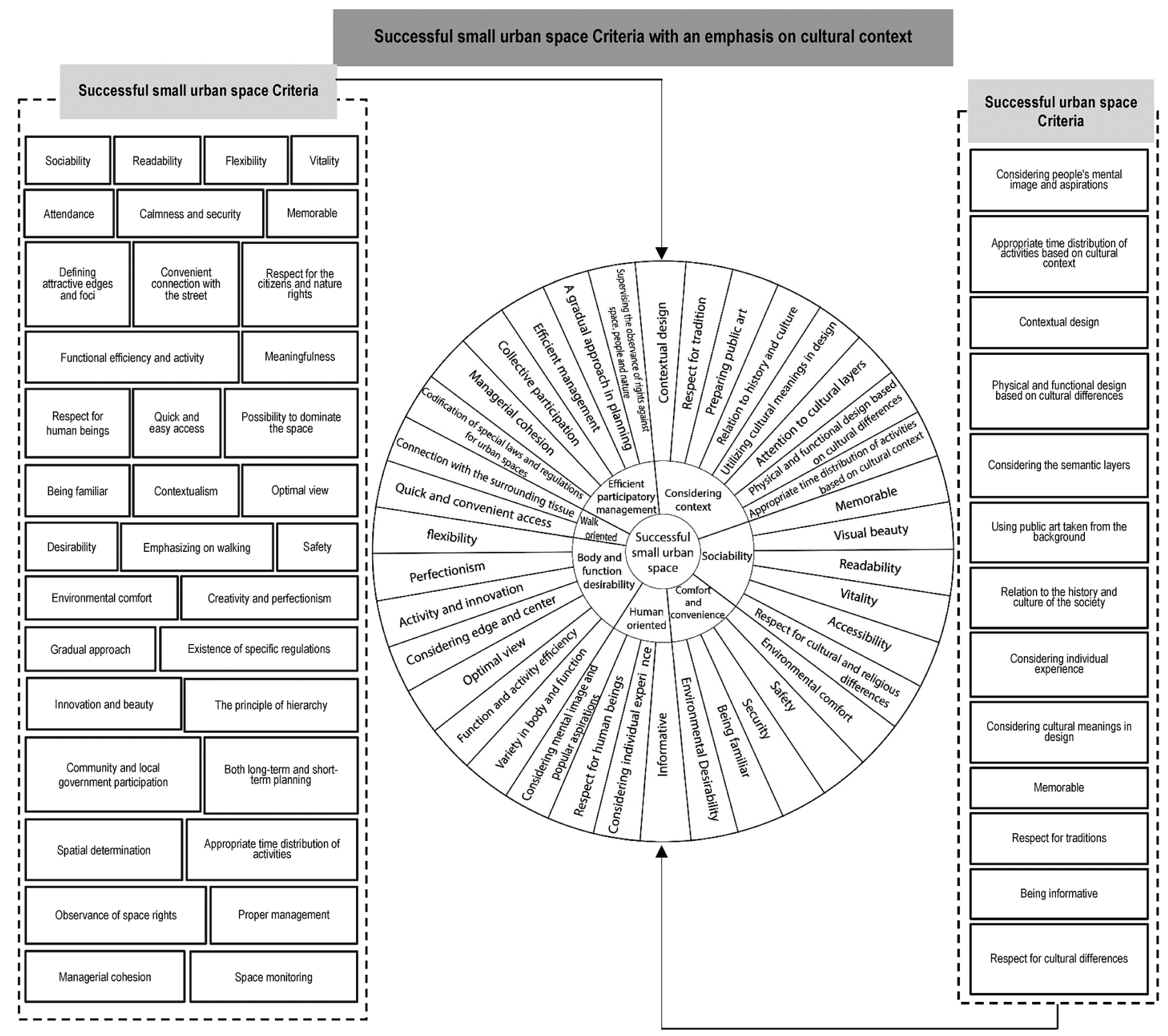

Figure 1 Conceptual model of successful small urban spaces with emphasis on cultural context

\section{CONCLUSION}

To summarizing the mentioned issues, the factors affecting the success of public spaces in general and small urban spaces, in particular, were combined in two categories of western countries and Iranian-Islamic cities, and those variables of public spaces. In general, they were used that were in line with the characteristics of small urban spaces and 
with Iranian Islamic culture, and inconsistent factors were removed. Finally, the conceptual model of the research is formulated as described in Fig. 1. In the right part of this model, the criteria of successful urban space are presented based on what was studied in the cultural context section. In this column, the researcher has developed criteria that are taken from the cultural context of each society and helps to consider cultural differences in the final model. On the left side of the model, the criteria for successful small urban spaces, which are presented in Fig. 1, are given. In the middle part of the model, the criteria of this research are stated. There are seven criteria: contextualism, sociability, comfort, human-centeredness, physical and functional desirability, pedestrianism, and efficient participatory management, each of which has sub-criteria - 38 sub-criteria are provided.

\section{REFERENCES}

[1] Naghizadeh, M. (2016). Analysis and design of urban space (principles, definitions, criteria, and methods). Tehran: University Jihad Publications.

[2] Efroymson, D., Ha, T. T. K. T., \& Ha, P. T. (2009). Public Spaces: How They Humanize Cities. Dhaka: HealthBridge, WBB Trust.

[3] Wang, L. \& Rongling, L. (2019). Study on the association mechanism between small public spaces and affective responses in the 'human-scale form' perspective-take Tianjin Wudadao Area as an example. International conference of city and territory in the globalization age.

[4] Nguyen, N. M. (2017). Towards the Making of User Friendly Public Space in China: An Investigation of the Use and Spatial Patterns of Newly Developed Small and Medium-Sized Urban Public Squares in Guangzhou and Shenzhen. PhD Thesis, Victoria University of Wellington. http://hdl.handle.net/10063/5654

[5] Shafer, S. \& Jacob, J. (2006). Urban Parks: The Value of Small Urban Parks, Plazas, and Other Outdoor Spaces. https://oaktrust.library.tamu.edu/bitstream/handle/1969.1/874 53/pdf_2399.pdf? sequence $=1 \&$ isAllowed $=\mathrm{y}$

[6] Christoffersen, A. (2010). The space between: Small-scale design for urban revitalization. The University of Georgia. Athens, GA.

[7] Whyte, W. H. (1988). The Design of Spaces (An article taken from the author's book "The city: Rediscovering the center"). University of Pennsylvania Press.

[8] Zukin, S. (2010). Naked City: The Death and Life of Authentic Urban Places. New York: Oxford University Press. https://doi.org/10.1093/oso/9780195382853.001.0001

[9] Gehl, J. (2013). Human city. Translation: Ghaffari, A., and Ghaffari, L. Tehran: Royal Architect Science Publications.

[10] Tonekaboni, B., Shahabian, P., \& Modiri, A. (2017). Recognition and analysis of socio-cultural changes and developments in public spaces of Tehran. Cultural Research Society Journal, 8(4), 133-158.

[11] Pakzad, J. (2006). Theoretical foundations and urban design process. Tehran: Samin Publishing.

[12] Isazadeh, K. (2017). Analyzing cognition of culture effect on body and design of cities with emphasis on cultural theories of design of biological complexes. Journal of Urban Management, 46, 71-96.

[13] Majedi, H. \& Saeedeh Zarabadi, Z. (2010). Marked city as a context-oriented city. Journal of Cultural Research, 3(3), 1-21. https://doi.org/10.1016/j.ccs.2010.04.002
[14] Talebi, J. (2004). Social relations in urban spaces. Journal of Social Science, 24, 161-180.

[15] Ujang, N. \& Zakariya, Kh. (2015). The notion of place, placemaking, and identity in urban regeneration. Preceding social and behavioral sciences, (170), 709-717. https://doi.org/10.1016/j.sbspro.2015.01.073

[16] Fazeli, N. A. (2020). Metropolis and culture; Anthropological researches on urban research, culture, and urban politics. Tehran: Farhameh Publications.

[17] Stevenson, D. (2009). Cities and urban cultures. Translation: Panahi, R. \& Poorahmad, A. Tehran: Publications of Urban Planning and Architecture Research and Publications Center.

[18] Smith, F. (2019). An Introduction to Cultural Theory. Translated by Pouyan, H. Sixth edition. Tehran: Cultural Research Office Publications.

[19] Salehi Amiri, R. (2007). Cultural concepts and theories. Tehran: Ghoghnoos press.

[20] Bashir, H. (2008). New semantics of communication: preparing for a deeper understanding of the relationship between culture and media. Cultural Research Journal, 1(3), 131-155.

[21] Negarestan, F., Teymouri, M., \& Atashinbar, M. (2010). Landscape theory, an approach to identity continuity in the process of urban renewal. Bagh-e Nazar Journal, 14, 59-68.

[22] Zukin, S. H. (2001). Urban culture: Whose city? Whose culture? Translation: Asadi, A. Journal of Urban and Rural Management, 8, 18-31.

[23] Rapoport, A. (1982). Urban design and human systems: on ways of relating the building to the urban fabric. Human and energy factors in urban planning: a systems approach. Series D: Behavioural and Social Sciences - 12. Proceedings of the NATO Advanced Study Institute. https://doi.org/10.1007/978-94-009-7651-1_12

[24] Corbett, N. (2014). Transformation of cities Renaissance of urban squares. Translation: Alizadeh, H. \& Keshavarzi, Sh. Tehran: Urban Development and Improvement Organization Publications.

[25] Berdi Anamoradnejad, R. (2011). Introduction to Urban Squares. Mazandaran: Mazandaran University Press.

[26] Soleimani, A. R. \& Asadi, M. (2017). Environmental psychology (ethics, behavior, and urban design). Tehran: Tahan Press.

[27] Ramon, G., Dolors, M., Ortiz, A., \& Prats, M. (2004). Urban planning, gender and the use of neighborhood of Barcelona. Journal of Cities, 21(3), 215-223. https://doi.org/10.1016/j.cities.2004.03.006

[28] Naghizadeh, M. (2018). Location in the good public domain of the city. Tehran: University Jahad Publications.

[29] Saeidnia, A. (1999). Municipal Green Book, Volume One: Urban Planning. Tehran: Publications of the Municipalities Organization.

[30] Lau, H. M. (2014). Investigating the small urban open spaces at high-density cities: A case study of Hong Kong. (Master). UPPSALA Universitet.

[31] de Cillo Malufe Spignardi, M. (2020). Lively Urban Spaces. In: Ghosh M. (eds) Perception, Design and Ecology of the Built Environment. Springer Geography. Springer, Cham. https://doi.org/10.1007/978-3-030-25879-5_24

[32] Gehl, J., Johansen, L., \& Reigstad, S. (2006). Close encounters with buildings. Urban design international, 11(1), 29-47. https://doi.org/10.1057/palgrave.udi.9000162

[33] Montgomery, J. (1998). Making a city: urbanity, vitality, and urban design. Journal of Urban Design, 3(1), 93-117. https://doi.org/10.1080/13574809808724418 
[34] Mc Guire, N. (2017). Tactical urbanism: A plan for the revitalization of vacant and decrepit spaces. The Equilibrium, 3(1), 16-23. https://doi.org/10.5070/Q23141220

[35] Shaftoe, H. (2008). Convivial Urban Spaces, Creating effective public spaces. London: Earthscan in the UK and USA.

[36] Abbaszadeh, S. H. \& Gohari, H. (2014). Meaningful spaces and social squares in Islamic urban planning are a lost element (interactive spaces) in Iranian-Islamic metropolises today. Journal of Sustainable City, 1, 164-191.

[37] Thornton, W. (2016). Differentiating small urban spaces as a type and idea. PhD Thesis, The University of Auckland.

[38] Joardad, S. D. \& Neill, L. W. (1978). The subtle differences in the configuration of small public spaces. Landscape Architecture Journal, 68(6), 487-491.

[39] Carmona, M., de Magalhães, C., \& Hammond, L. (2008). Public space: the management dimension: Psychology Press. https://doi.org/10.4324/9780203927229

[40] Tehran Studies and Planning Center. (2018). Tehran Urban Space Management Strategic Document. Danesh Shahr Publications.

\section{Authors' contacts:}

\section{Parvin Partovi, Professor}

University of Art,

\# 56, Sakhai St., Hafez ave., Tehran 1136813518, Iran

Kebria Sedaghat Rostami, PhD candidate in Urban Planning

(Corresponding Author)

University of Art,

\# 56, Sakhai St., Hafez ave., Tehran 1136813518, Iran

kebriasedaghat@chmail.ir

Amir Shakibamanesh, Associated Professor

University of Art,

\# 56, Sakhai St., Hafez ave., Tehran 1136813518, Iran 